\title{
Revista
}

Triângulo

\section{REFLEXÕES SOBRE O PROCESSO DE ENSINO: A SEQUÊNCIA DIDÁTICA À LUZ DA ANÁLISE LINGUÍSTICA}

\section{REFLECTIONS ABOUT THE TEACHING PROCESS: THE DIDACTIC SEQUENCE BASED ON LINGUISTIC ANALYSIS}

\author{
Liliane Nunes Santos ${ }^{1}$ e Bruno Curcino Mota $^{2}$
}

\begin{abstract}
RESUMO
O objetivo central desse artigo é discorrer sobre a importância do desenvolvimento de técnicas de ensino da Língua Portuguesa consonantes com a Análise Linguística. Para tanto, aplicamos uma sequência didática a alunos do $6^{\circ}$ ano do Ensino Fundamental, tendo como foco a transposição do discurso direto para o discurso indireto, o uso de termos anafóricos e a utilização do pretérito nas formas verbais, utilizando como ferramenta histórias em quadrinhos.
\end{abstract}

PALAVRAS-CHAVE: Análise Linguística. Didática. Texto.

\section{ABSTRACT}

The main goal of this article is to discourse about the importance of the development of teaching techniques from the Portuguese language according to the Linguistic Analysis. So that, we have applied a didactic sequence for our $6^{\text {th }}$ grade Elementary School students, focusing on the transposition from the direct speech into the indirect speech, the use of anaphoric terms and the past tenses, having cartoons as our main tools.

KEYWORDS: Linguistic Analysis. Didactic. Text.

\section{INTRODUÇÃO}

O professor de língua portuguesa vivencia uma realidade dicotômica: por um lado o ensino centrado nos exercícios estruturais da gramática normativa e descritiva; por outro um processo baseado na leitura e escrita de textos aliadas à práticas sociais significativas e integradas, focalizando a análise linguística de problemas encontrados na produção textual.

\footnotetext{
${ }^{1}$ Universidade Federal do Triângulo Mineiro - UFTM. Programa de Pós-Graduação Mestrado Profissional em Letras (PROFLETRAS). E-mail: lilins.ln@gmail.com

${ }^{2}$ Universidade Federal do Triângulo Mineiro - UFTM. Programa de Pós-Graduação Mestrado Profissional em Letras (PROFLETRAS). E-mail: brcurcino@uol.com.br
} 
É corrente a crença de alunos (e de muitos professores) de que a aula de Português é destinada ao ensino de classes gramaticais e normas ortográficas, privilegiando unicamente a linguagem formal, variante de maior prestígio em nossa sociedade. No entanto, sabemos que seu objeto de estudo deve ir muito além de meras definições, priorizando o domínio das habilidades da língua em situações concretas de interação, a produção de enunciados, entre outros. GERALDI (1997, p.119) ressalta que

Confunde-se estudar a língua com estudar Gramática, e a gramática, tal qual de ordinário se cursa nas escolas, não só não interessa à infância, não só, enquanto aos benefícios que se lhe atribuem, se reduz a uma influência totalmente negativa, senão que onde atua positivamente, é como elemento de antagonismo ao desenvolvimento intelectual do aluno.

Alguns profissionais, no entanto, percebendo a necessidade de mudanças desse quadro, buscam alternativas através de outras teorias. Devido à flexibilidade dos modelos de ensino, que recorrem a diferentes caminhos teórico-metodológicos, é possível encontrar uma mescla de perspectivas: a abordagem tradicional do ensino da língua materna - leia-se ensino centrado na gramática - aliada às novas práticas exploradas pela Análise Linguística, como afirma MENDONÇA (2006, p. 201):

\begin{abstract}
A tentativa de aliar uma nova perspectiva a formas conhecidas de ensinar é natural num processo de apropriação, por parte do docente, de uma proposta teórico- metodológica diferente da sua prática cotidiana. Isso se explica porque não é possível, para o professor, desvencilhar-se da sua própria identidade profissional. (...) Nesse sentido, atravessamos um momento especial, em que convivem "velhas" e "novas" práticas no espaço da sala de aula de gramática, por vezes, conflituosas.
\end{abstract}

A preocupação do docente deve centrar-se na aprendizagem da criança, cuja aquisição da linguagem efetua-se através da produção de sentidos em textos que promovam a interação e não por meio do estudo da palavra isolada. Segundo MENDONÇA (2006, p. 203) "o fluxo natural da aprendizagem é: da competência discursiva para a competência textual até a competência gramatical (também chamada por alguns de competência linguística)." Não estamos aqui defendendo a abolição do ensino da gramática, porém acreditamos que é necessário dar ao aluno ferramentas para desenvolver o exercício da linguagem para que, a partir disso, ele tenha condições para deduzir a teoria das leis que regem o processo gramatical. Como afirma GERALDI (1997, p. 120): “Aprender a respeito da língua, tomar 
consciência dos mecanismos estruturais do sistema linguístico deve ser a etapa posterior: levar o aluno à consciência da língua só depois de ter ele a posse da língua."

O professor deve ter em mente sua função de formar usuários da língua autônomos e não criar gramáticos ou linguistas descritivistas. Priorizar o ensino da gramática é um erro, pois segundo FARACO (1984, p. 20) "O que lhe oferecemos é apenas uma meta-língua (conceitos, regras, exceções...), na ilusória certeza de estarmos ensinando a língua". Mas como poderá mudar toda uma prática de ensino que vem desenvolvendo ao longo dos anos? A Análise Linguística surge como alternativa para amenizar, ou quiçá, acabar com essas dificuldades, contrapondo-se ao ensino tradicional da gramática. Utilizaremos a tabela abaixo, formulada de acordo com MENDONÇA (2006, p. 207), para ilustrar as premissas da Análise Linguística:

Concepção da língua como ação interlocutiva situada, sujeita às interferências dos falantes. Integração entre os eixos de ensino: a Análise Linguística é ferramenta para a leitura e produção de textos.

Metodologia reflexiva, baseada na indução (observação de casos particulares para a conclusão das regularidades/regras.

Trabalho paralelo com habilidades metalingüísticas e epilinguísticas.

Ênfase nos usos como objetos de ensino (habilidades de leitura e escrita), que remetem a vários outros objetos de ensino (estruturais, textuais, discursivos, normativos), apresentados e retomados sempre que necessário.

Centralidade dos efeitos de sentido.

Fusão com o trabalho com os gêneros, na medida em que contempla justamente a intersecção das condições de produto dos textos e as escolhas linguísticas.

Unidade privilegiada: o texto.

Como percebemos, o foco da Análise Linguística não é a simples memorização de termos descritivos da língua; seu objeto de estudo será entre outros, o uso da língua e os mecanismos articuladores dos efeitos de sentido no texto.

A análise linguística a se praticar em sala de aula não é a simples correção gramatical de textos face a um modelo de variedade e de suas convenções: mais do que isso, ela permite aos sujeitos retomar suas intuições sobre a linguagem, aumentá-las, torná-las conscientes e mesmo produzir, a partir 
delas, conhecimentos sobre a linguagem que o aluno usa e que outros usam. (GERALDI, 1997, p. 217)

Cabe aqui frisar a importância de fazer do texto o objeto de estudo da língua portuguesa, o ponto de partida e chegada de todo o processo de ensino, visto que é a unidade máxima de funcionamento da língua. MARCUSCHI (2008, p. 68) afirma que "a comunicação linguística (e a produção discursiva em geral) não se dá em unidades isoladas, tais como fonemas, morfemas ou palavras soltas, mais sim em unidades maiores, ou seja, por textos."

Certa da importância em seguir uma prática docente voltada à Análise Linguística, desenvolvi uma sequência didática com uma turma de alunos de $6^{\circ}$ ano na qual atuo como professora de Língua Portuguesa.

O objetivo central da sequência é mostrar o desenvolvimento das habilidades dos alunos nas produções textuais realizadas, tendo como foco a transposição do discurso direto para o indireto, o uso de elementos anafóricos e o pretérito nas formas verbais.

\section{Desenvolvimento da sequência didática}

Para iniciar a sequência didática, pedi que um aluno (João) falasse algo para outra aluna (Maria). O aluno disse "Você é bonita". Transcrevi na lousa a fala do aluno, explicando à classe que no texto escrito devemos utilizar o travessão para marcar a fala de algum personagem. Além disso, expliquei o uso dos verbos dicendi como estratégia de tipificação da fala. Desse modo, foi produzido o seguinte texto na lousa:

João disse:

--- Você é bonita.

Em seguida, pedi que outro aluno informasse o que João havia dito para Maria. O aluno respondeu Você é bonita. Expliquei então que ao reproduzir a fala de outra pessoa deveríamos utilizar uma forma diferente, que consiste em usar nossas próprias palavras para expressar o que o outro havia falado. Fiz algumas perguntas aos alunos, e conforme respondiam, escrevi as respostas na lousa, da seguinte maneira:
P: Quem disse algo?
R: João.
P: Disse para quem?
R: Disse para Maria.
P: O que disse?
R: Que ela é bonita. 
A frase formada na lousa foi João disse para Maria que ela é bonita. Nesse momento expliquei aos alunos que ao reproduzir a fala de alguém com nossas palavras devemos utilizar os verbos no pretérito, pois a ação narrada já aconteceu. Dessa forma, os alunos corrigiram a frase, que resultou em João disse para Maria que ela era bonita.

Somente após essas explicações introduzi as nomenclaturas discurso direto e discurso indireto. Tal atitude foi tomada porque, baseando-me na Análise Linguística , acredito que entender os mecanismos do discurso logo no início torna a percepção das nomenclaturas mais fácil e significativa para os alunos. Além do que, como afirma MENDONÇA (2006, p. 217) "a nomenclatura é mais uma ferramenta no processo de aprendizagem, o que não equivale a eleger como objetivo das aulas o domínio dos termos técnicos."

Após esse momento, utilizei a dinâmica do telefone sem fio para propiciar maior compreensão dos elementos dos discursos direto e indireto. A dinâmica consiste em dizer uma frase para o primeiro aluno da fila, que repetirá o que ouviu para o segundo aluno, e assim consecutivamente até chegar ao último aluno da fila, que deverá contar o que ouviu, porém utilizando o discurso indireto. As frases ditas pelos últimos alunos eram escritas na lousa e eu aproveitava esse momento para esclarecer as dúvidas sobre o uso do pretérito e dos verbos dicendi.

Quando a turma demonstrou entender os tipos de discurso e como utilizá-los, pedi que observassem uma história em quadrinhos que já havia sido analisada em aulas anteriores. 

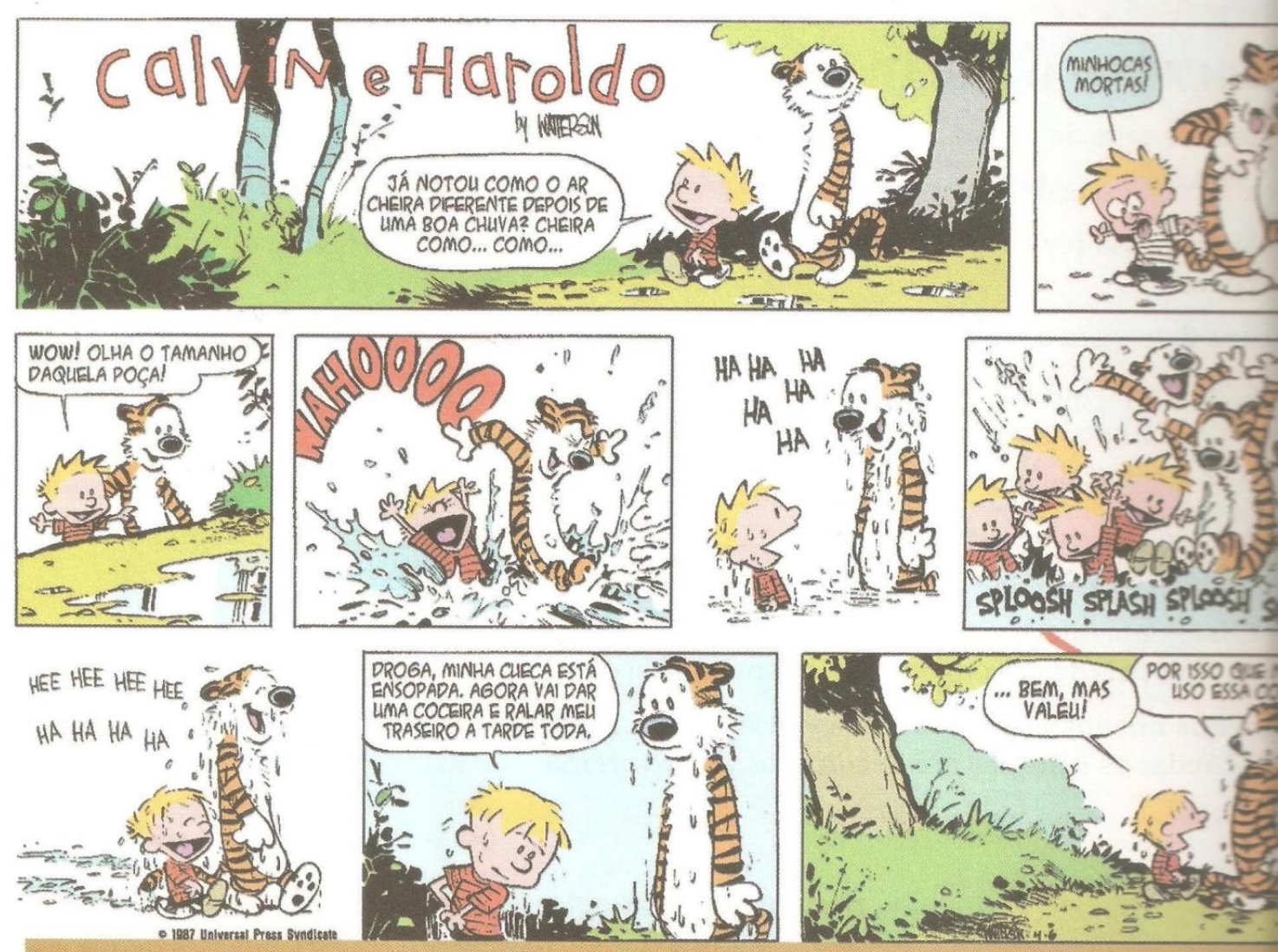

Bill Watterson. Disponivel em: <http://depositodocalv

Ilustração 1: Primeira história em quadrinhos analisada

Expliquei que as frases dos balões eram discurso direto, pois representavam a fala das personagens, e que se fossem reproduzidas em um texto narrativo seriam precedidas por travessão. Dito isso, solicitei aos alunos que criassem um texto narrativo baseado na história em quadrinhos lida, porém utilizando apenas o discurso indireto.

Após a entrega dos textos, efetuei a correção e constatei que a maioria dos alunos descreveu o espaço e o enredo de maneira detalhada, porém ainda utilizando o discurso direto. Diante dessa percepção, selecionei uma produção textual da aluna G.S.C: 


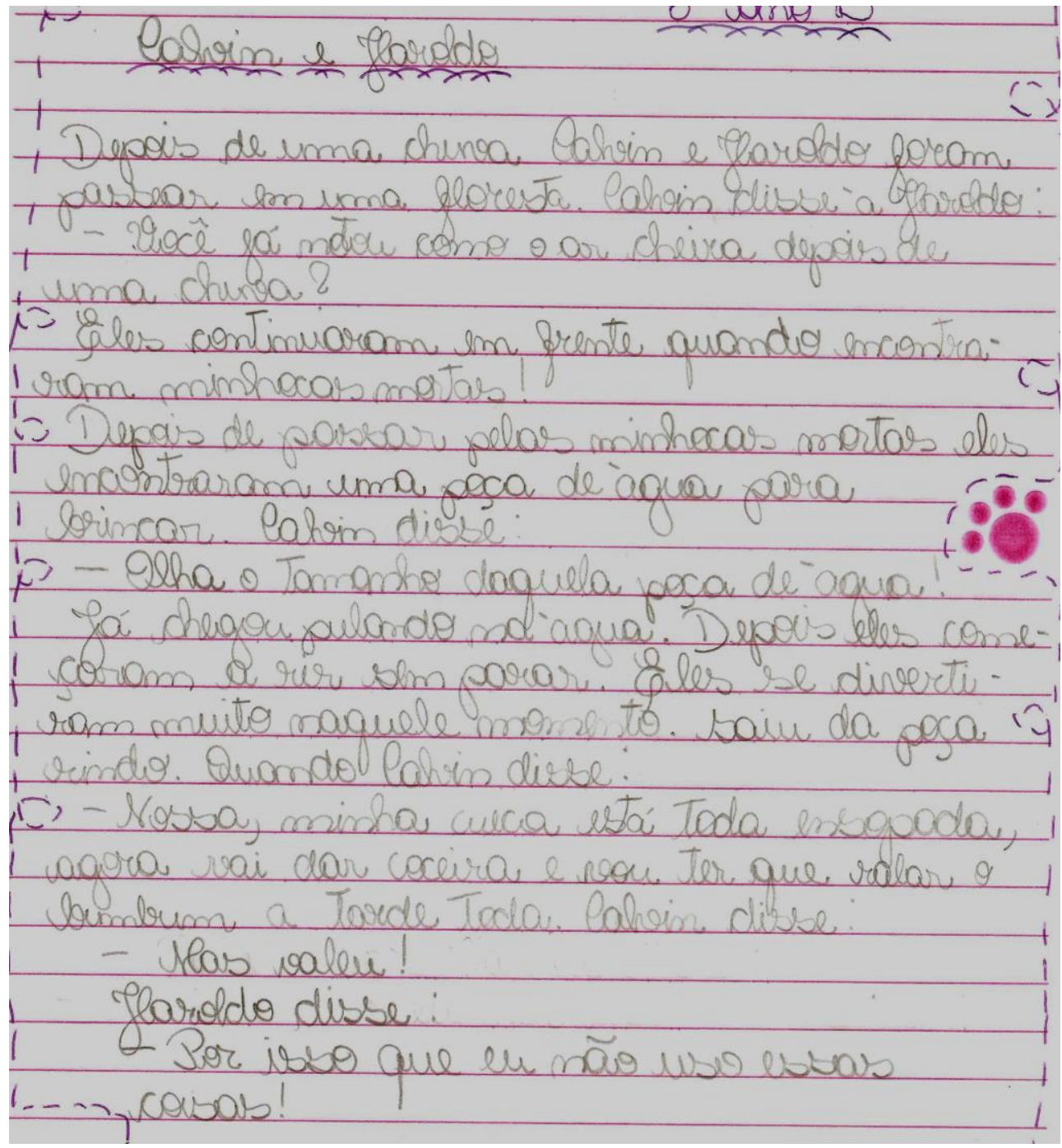

Illustração 2: Produção textual de G.S.C

Fiz cópias para os alunos, dividindo-os em duplas. Primeiramente, pedi que lessem o texto e anotassem o que não estava de acordo com a proposta inicial. Os alunos logo perceberam que o texto continha trechos em discurso direto. Dessa forma, sugeri que fizéssemos juntos a correção da redação apresentada.

A realização dessa atividade foi muito interessante, pois tem como foco o desenvolvimento da capacidade do aluno escolher, entre as diversas possibilidades da língua, a que melhor atende à pretensão de sentido. $\mathrm{O}$ fato de a correção ter sido realizada coletivamente foi fundamental para o resultado, como demonstra MENDONÇA (2006, p.215):

Como estratégias didáticas, pode-se trabalhar com a avaliação da produção por parte dos colegas, com a comparação entre textos produzidos e entre estes e outros textos, com a escolha de alguns exemplos para atividades 
individuais ou coletivas. Nesses momentos, o professor conduz a reflexão, reescrita de trechos/ textos e, principalmente, a sistematização dos conhecimentos construídos.

Os alunos deram sugestões desde o título até as linhas finais, e ficavam contentes quando sua opinião era aceita pelo restante da classe. Diante dessa situação, refleti que é preciso manifestar aos estudantes nosso interesse em ouvir o que eles têm a dizer. De acordo com BAJARD (1994, p. 109, 111-2):

O interesse em ouvir supõe que se atribua ao dizer uma função comunicativa que requer não só a língua, mas também a contribuição de outras linguagens... O dizer socializa o texto escrito e não pode ser reduzido nem a um meio de atingir o sentido, nem a uma avaliação de leitura. É necessário cultivar essa atividade, sem esquecer a sua função principal que é a comunicação. Para isso, a criança que diz um texto deve cumprir o papel de emissor e saber ser escutado pelo ouvinte. O dizer participa assim da comunicação entre professor e alunos. Praticar o dizer permite socializar a escrita de maneira mais imediata e mais exeqüível do que através de publicações.

A aula dialogada foi uma experiência muito interessante, já que possibilita maior interação entre alunos e professor. Segundo LIBÂNEO (1994, p. 168), "a conversação didática é elemento característico do método de elaboração conjunta. Não se propõe apenas em produzir respostas dos alunos para perguntas sobre algo que o professor já pensou e falou. A conversação didática é aberta e seu resultado supõe a contribuição de professor e alunos."

Tal prática é, a meu ver, mais eficiente do que aquela comumente realizada, quando o aluno produz o texto, entrega para o professor e o ciclo se encerra. Quando escreve, o aluno espera um retorno do professor sobre o seu texto, nisso consiste a interação discursiva. Mas o que recebe na maioria das vezes é um emaranhado de correções ortográficas, a típica higienização textual. LEAL (2005, p. 55) ressalta que "esse sujeito aprendiz encontra-se destituído das reais possibilidades de interação.O aluno passou a palavra ao professor para ser lido e não para obter um conceito ou ser enquadrado em categorias que o classificam, que buscam verificar onde há erro ou onde há acerto.”

Em meio às sugestões dadas pelos alunos, apresentei a variedade de verbos dicendi, explicando que a escolha do verbo pode especificar ainda mais a ação como falar, sussurrar, gritar, etc. Nessa parte do processo, os alunos demonstraram empenho em melhorar o texto, extraindo, acrescentando e ligando as sentenças. Com isso o texto começou a parecer mais 
coeso para eles, a soar melhor. Quanto à intervenção do professor, de acordo com (PASSARELLI, 2011), deve desempenhar além do papel de correvisor ao orientar a reescrita durante a revisão do texto, a intervenção no produto final.

Ao final da correção do texto, os alunos copiaram a versão final da lousa, comentando que haviam gostado muito da aula, que "fazer redação desse jeito é mais divertido".

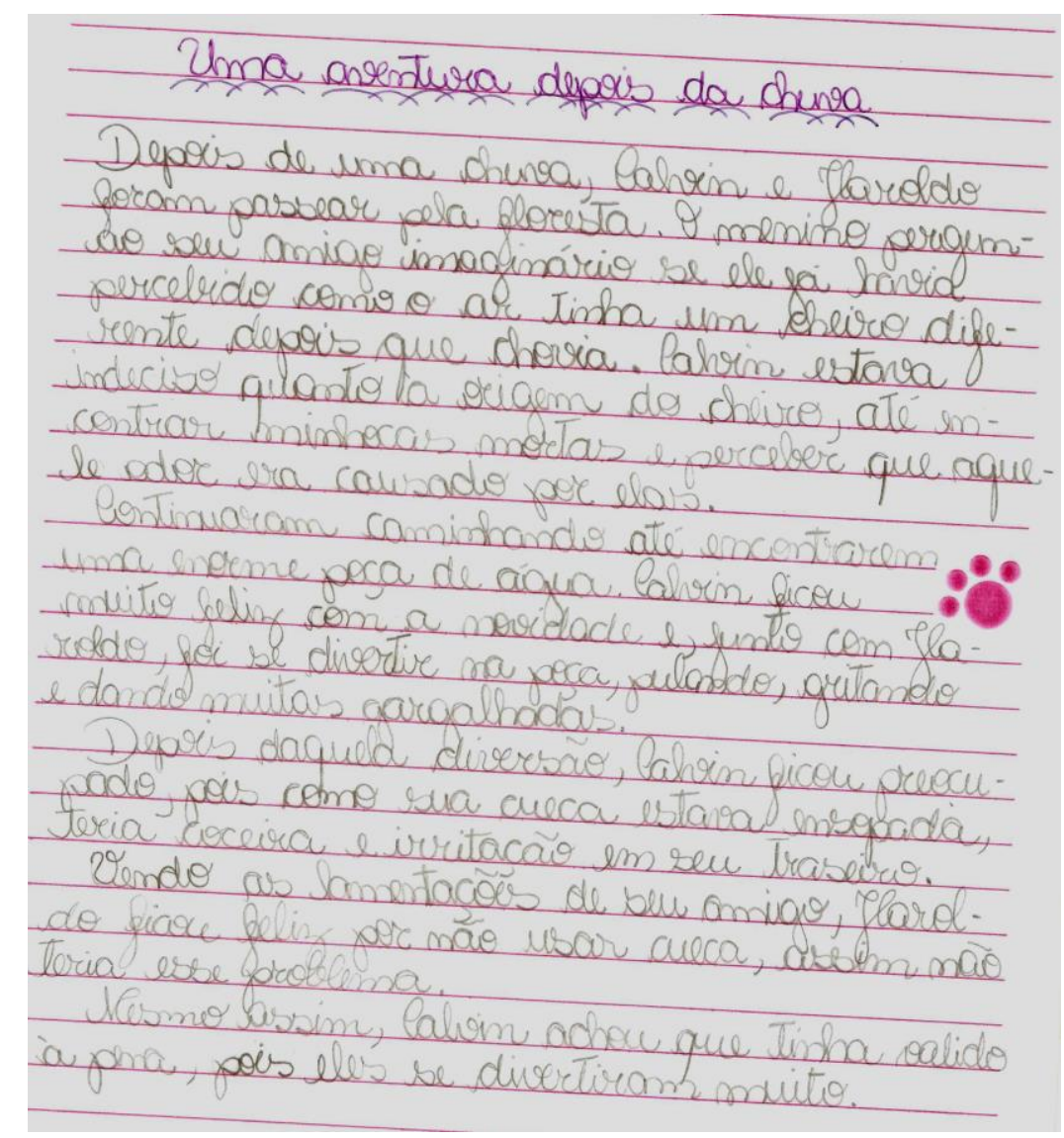

Ilustração 4: Versão final produzida coletivamente pelos alunos.

Para a próxima etapa, entreguei uma nova história em quadrinhos para a classe e pedi que fizessem outro texto narrando os acontecimentos da HQ utilizando apenas discurso indireto. Salientei ainda a importância de escolher os verbos dicendi adequados para cada situação, o uso do pretérito, além de usar termos anafóricos para retomar os personagens, evitando a repetição. Os alunos começaram a produzir o texto em sala, mas com o término do horário, puderam finalizá-lo em casa, entregando na aula do dia seguinte.

Ao analisar as produções textuais, considerei o resultado satisfatório, uma vez que quase todos os alunos utilizaram apenas o discurso indireto, fazendo uso do pretérito de maneira adequada. Outro aspecto que merece destaque é o cuidado com a escolha vocabular, 
a começar pelo título que deixou de ser óbvio, assumindo nuances pitorescas, como podemos observar em alguns textos que foram selecionados:

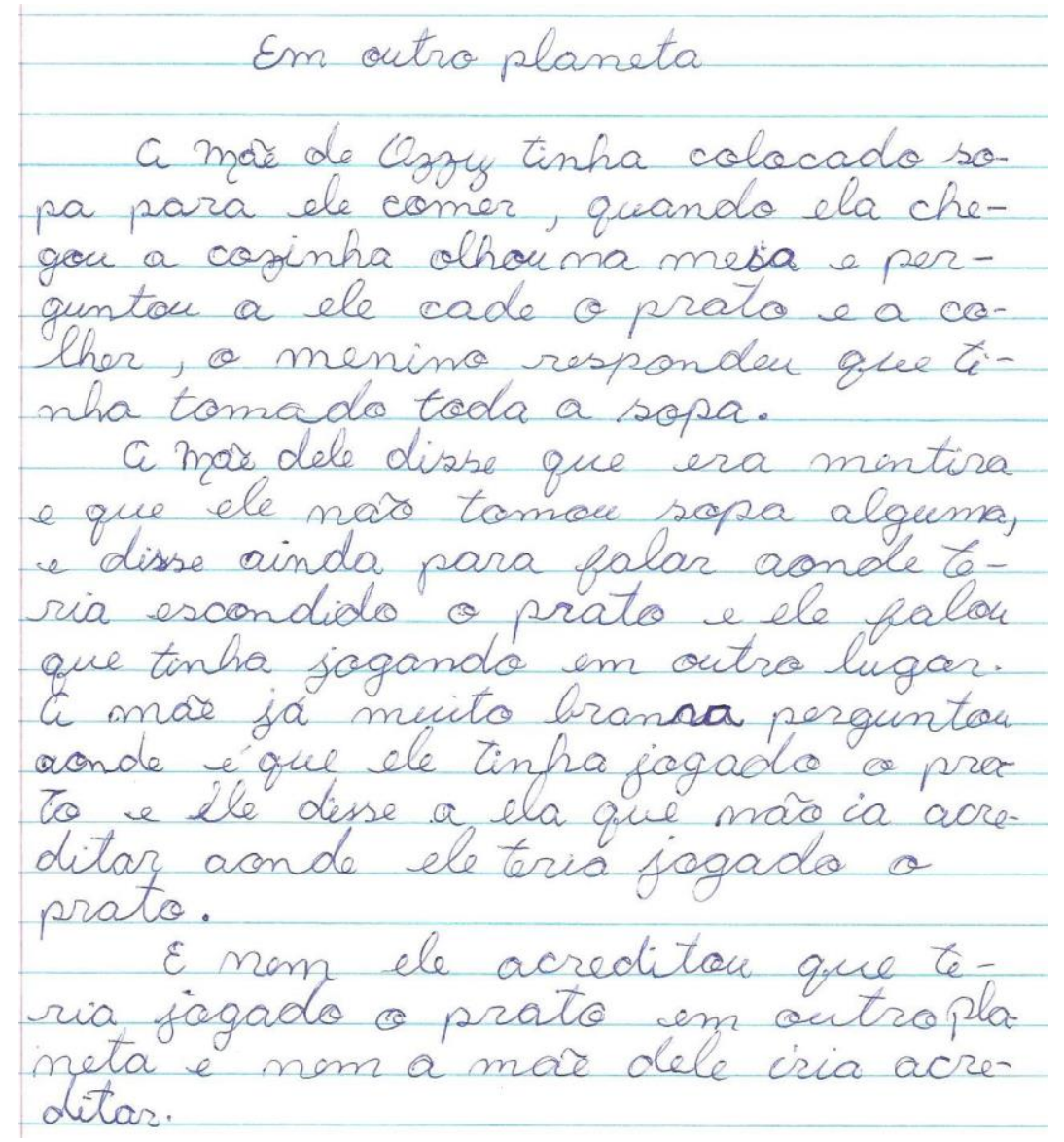

Ilustração 5: Produção textual da aluna A.M.C.S 


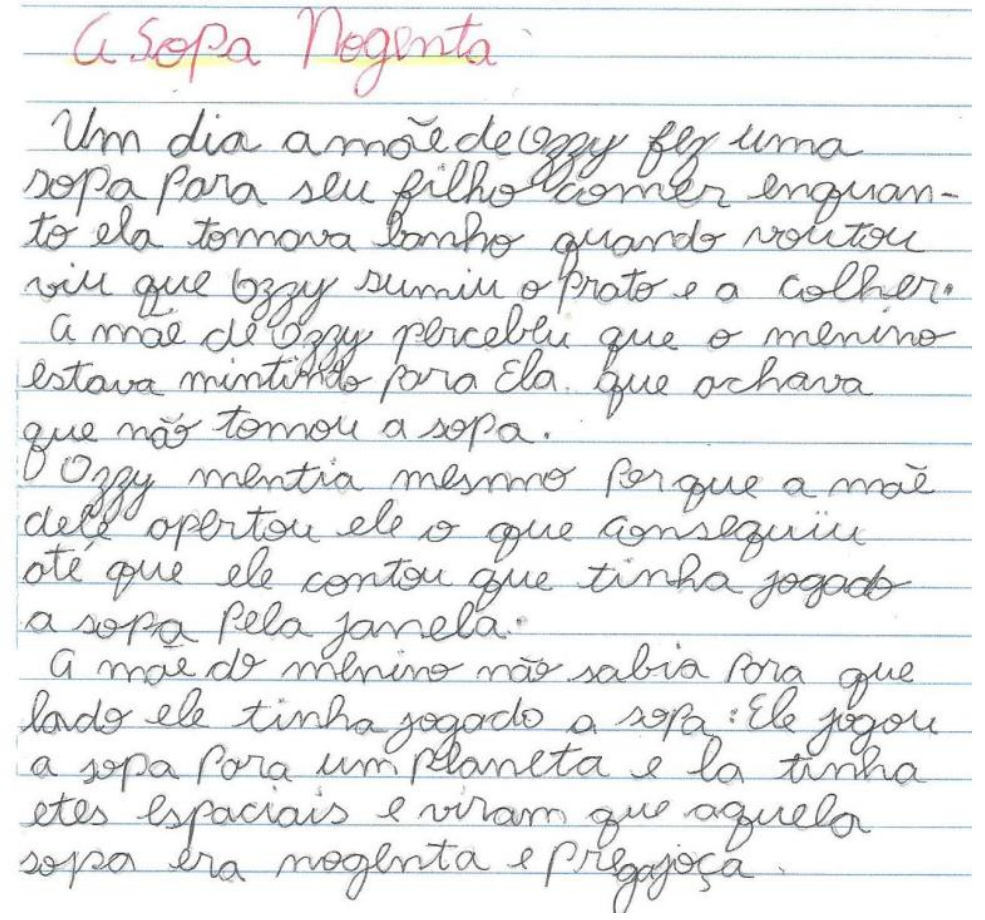

Ilustração 6: Produção textual do aluno L.A.O 


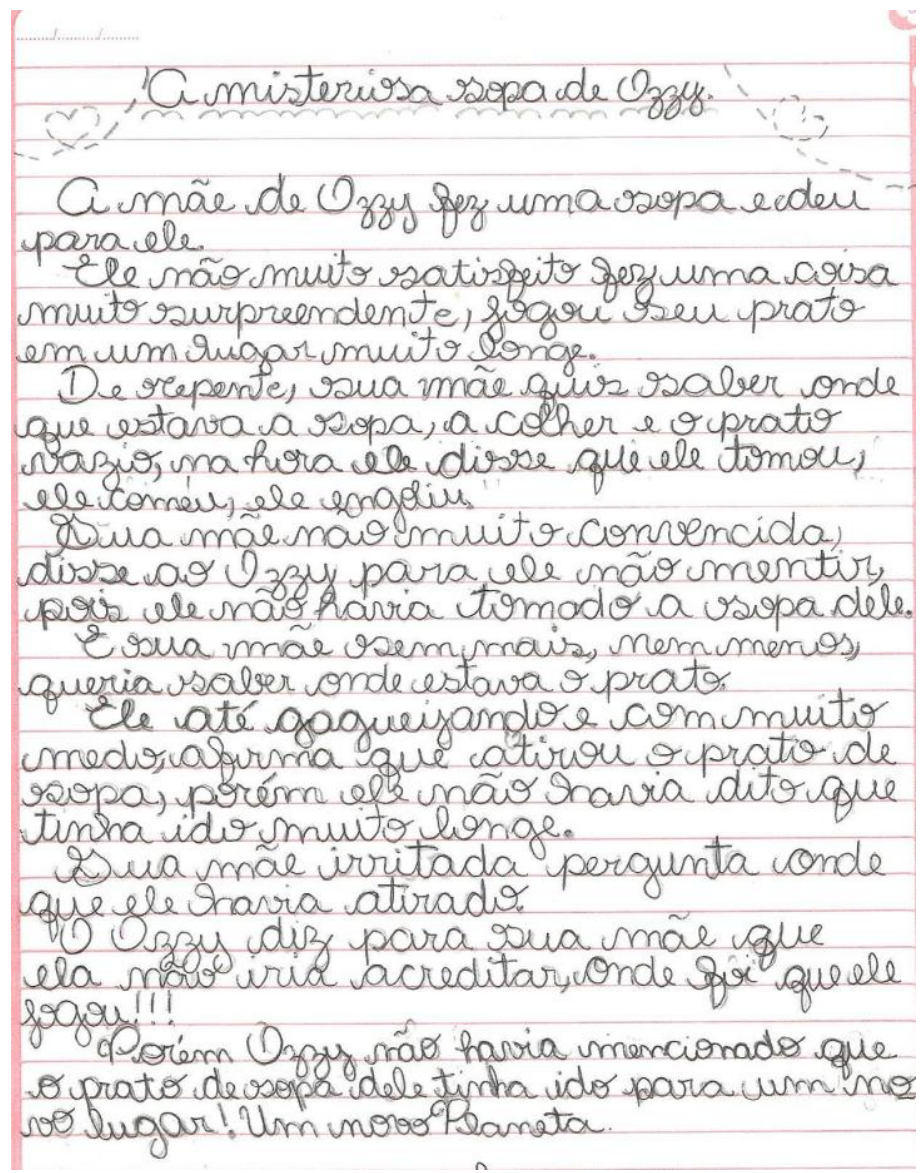

Ilustração 7: Produção textual da aluna G.V.F

Outra reflexão feita deve-se ao fato de não ter "marcado" os textos dos alunos com caneta vermelha, apontando erros, como costumeiramente fazia. Atendi cada um individualmente, apontando as falhas de seu texto, explicando em que consistia cada uma e sugerindo melhorias, sempre utilizando linguagem clara para que pudesse ser compreendida. Dessa forma, acredito que a auto-estima do aluno não ficou abalada por sentir-se inferior àqueles que não tinham seus textos repletos de correções no que tange à ortografia, coesão, coerência ou paragrafação, por exemplo. Busco para isso respaldo no que BACH (1991, p. 239) postula:

A observação deveria ter por finalidade abrir os olhos do aluno, tornar-lhe o erro perceptível, pois que, para progredir, ele deve perceber o erro. Numa tal perspectiva, termos como vago, mal dito, impreciso...são de eliminar. Eles não permitem ao aluno compreender em que tropeçou, impedindo, ao mesmo tempo, toda a esperança de progressão. Para guiar o melhor possível o trabalho de reescrita, aquele que corrige, pelo contrário, terá o cuidado de diferenciar os problemas encontrados e de enunciar numa linguagem clara, que representa um ponto real de apoio. 
A escolha pelo gênero história em quadrinhos deu-se porque, além de agradar as crianças com o uso da linguagem visual, havia naquele momento o estudo da turma sobre as linguagens verbal, não verbal e mista. A leitura da história em quadrinhos exige tanto a interação entre as linguagens como também a apreensão de cada quadro em particular e, ainda, o conjunto de quadrinhos para, de fato, haver entendimento. Ao fazer essa leitura, o estudante associa os elementos do vocabulário, da espacialidade, da visualidade, etc.

O fascínio que as crianças têm pelos quadrinhos é tão grande que mesmo com a possibilidade de que os estudantes realizem sua leitura autônoma, o Programa Nacional Biblioteca da Escola (PNBE), passou a contemplar esse gênero na composição de seus acervos, desde 2006.

Provavelmente o gosto infantil contribuiu para que as histórias em quadrinhos deixassem de ser banidas pela escola e fossem autorizadas a estar nas classes. Mesmo que sejam bem aceitas pelos estudantes, a leitura das mesmas exige habilidades que vão além da compreensão da palavra, já que o leitor precisa articular palavra, imagens, balões, ordem das tiras, onomatopeias, entre outros elementos que contribuem significativamente para a independência do leitor. A leitura de quadrinhos pressupõe o estabelecimento de relações entre os códigos, gerando novas potencialidades de significação. (RAMOS, 2011, p.221)

\section{CONSIDERAÇÕES FINAIS}

Ao pautarmos nossa prática docente na Análise Linguística temos a possibilidade de realmente desenvolver um trabalho efetivo no ensino de Língua Portuguesa, visto que a competência discursiva é construída através da leitura e produção, tendo como objeto de ensino a linguagem. Fica claro que através desse método as competências textuais, discursivas, linguísticas e gramaticais são alcançadas em sua totalidade, ao contrário das técnicas baseadas no ensino da Gramática como ponto de partida, que prioriza a memorização de definições da estrutura da língua.

Porém, esbarramos na dificuldade de mudança: da escola, da grade curricular, dos livros didáticos, daquilo que aprendemos enquanto alunos, de nossa própria ideologia. Além disso, é necessário maior clareza quanto ao método, aos termos de ensino da Análise Linguística, visto que essa não se caracteriza como uma prática intuitiva, em que o professor não segue uma sistematização do processo de ensino, como muitos acreditam. Reflexões 
devem ser realizadas acerca dessa temática, buscando melhorar a qualidade das aulas de Língua Portuguesa. Os alunos - que são as grandes vítimas dessa dicotomia Análise Linguística versus Gramática - agradecem.

\section{REFERÊNCIAS}

BACH, Pierre. O prazer na escrita. Rio Tinto: Edições Asa/ Clube do Professor, 1991.

BAJARD, Elie. Ler e dizer: compreensão e comunicação do texto escrito. São Paulo: Cortez, 1994.

FARACO, Carlos Alberto. As sete pragas do Ensino de Português. In: GERALDI, João Wanderley. O texto na sala de aula. 2. ed. Cascavel, ASSOESTE, 1984.

GERALDI, João Wanderley. Portos de passagem. 4. ed. São Paulo: Martins Fontes, 1997.

LEAL, Leiva de F.V. A formação do produtor de texto escrito na escola: uma análise das relações entre processos interlocutivos e os processos de ensino. In: VAL, Maria da Graça C. Reflexões sobre práticas escolares de produção de texto: o sujeito-autor. Belo Horizonte: Autêntica/ CEALE/ FaE/ UFMG, 2005. p. 53-68.

LIBÂNEO, José Carlos. Didática. São Paulo: Cortez, 1994.

MARCUSCHI, Luiz Antônio. Produção textual, análise de gêneros e compreensão. São Paulo: Parábola Editorial, 2008.

MENDONÇA, Márcia. Análise lingüística no ensino médio: um novo olhar, um outro objeto. In: BUNZEN, Clécio e MENDONÇA, Márcia. Português no ensino médio e formação do professor. São Paulo: Parábola Editorial, 2006.

PASSARELLI, Lílian Maria Ghiuro. Ensino e correção na produção de textos escolares. São Paulo: Telos, 2012.

RAMOS, Flávia Broccheto e FEBA, Berta Lúcia Tagliari. Leitura de história em quadrinhos na sala de aula. In: SOUZA, Renata Junqueira e FEBA, Berta Lúcia Tagliari. Leitura literária na escola. Campinas, SP: Mercado de Letras, 2011.

RECEBIDO EM: 06/03/2016

APROVADO PARA PUBLICAÇÃO EM: 29/11/2016 